\title{
A Study on Various Pasting and Textural Parameters of Chana Flour Incorporated Extruded Product
}

\author{
Devendra Kumar Bhatt, Shweta Verma \\ Institute of Food Technology (A Centre of Excellence) Bundelkhand University, Jhansi (U.P.), India
}

\begin{abstract}
Extrusion cooking technologies are used for cereal and protein processing in food products. In this study extruded products were prepared by using six different levels of chana flour i.e. 5\%, 10\%, 15\%, 20\%, $25 \%$ and $30 \%$ respectively. Among all the samples including the control one, the one which secured highest overall acceptability score was T5 (20\% chana flour). Results found in this study showed that higher chana flour level could also contribute to the reduction in expansion and increased in bulk density. Study revealed that treated extrudates required more force to breakdown with increased level of chana flour. It is also the main source of protein hence incorporation of chana flour enhances the nutrient content of puff product. RVA analysis results indicate that the chana flour had low peak viscosity due to protein content and it is also showed that peak time increased with the increased level of protein.
\end{abstract}

Keywords: extruded puff snack; physic-chemical properties; sensory quality; pasting viscosity; hardness.

\section{Introduction}

Extrusion is a very widely used technology in the food industry. Some of the common food products made with extrusion technology include snacks, breakfast cereals, flat breads, bread crumbs, pellet products, textured vegetable proteins and many others. Extruded products are typically made by utilizing a raw material, often flour, and subjecting it to high temperatures while also creating a high shear and high pressure environment using rotating screws. It is a complex process with multiple inputs variables. Extrusion can be viewed as a reactor with a short residence time and with numerous options to control the energy inputs. The food ingredients in extrusion undergo physico-chemical changes as they are subjected to mechanical shear and heat. These physico-chemical changes transform them into the products with different eating characteristics. Extrusion cooking is a high-temperature, short-time process in which moistened, expansive, starchy and/or protenacious food materials are plasticised and cooked in a tube by a combination of moisture, pressure, temperature and mechanical shear, resulting in molecular transformation and chemical reactions $[1 ; 2]$. Extrusion cooking modifies the digestible characteristic and functional properties, such as paste viscosity, water absorption and water solubility indexes, expansion index and bulk density of protein and starch molecules [3; 4]. Processing of various foodstuffs with extrusion cooking represents a very effective process applicable in biotechnology and food industry while products of extrusion cooking are of major importance today as well [5]. In the Indian subcontinent, chickpea is split (cotyledons) as dhal and ground to make flour (besan) that is used to prepare different snacks [6;7]. The pasting properties of starch might give useful information related to the quality of extruded product. The useful properties of chicjkpea may be incorporated in the final products.

\section{Material And Methods}

All the materials were purchased from local market of Jhansi. An extrusion process was conducted with different proportions of corn flour, rice flour and chana flour. Corn flour and rice flour were mixed in a proportion of $60-40$ and moisture was adjusted to $16 \%$. Snack prepared from corn flour and rice flour in this ratio served as control sample. The chana flour was blended at six different compositions 5\%,10\%, 15\%, 20\%, 25\% and $30 \%$. Similar amount of salt $(1.6 \%)$ and food colour $(0.4 \%)$ were also added in blends. The blended samples were mixed thoroughly or passed through 10 mesh size sieve twice to get a homogenous mixture and tempered by adding a predetermined amount of water $(6 \%)$. kept for 1-2 hour at room temperature for moisture equilibrium and then fed into the extruder hopper. The extruder conditions were 1 st heater temperature $120^{\circ} \mathrm{C}$ and 2 nd heater temperature set on $60^{\circ} \mathrm{C}$. First put moist feed with $25 \%$ moisture and optimum extrusion speed $350 \mathrm{rpm}$. The input feed rate was set at $15 \mathrm{rpm}$. The cutter (with flour blades) speed was set to $150 \mathrm{rpm}$.

Table 1. Details of treatments

\begin{tabular}{|c|c|c|c|c|c|c|c|}
\hline \multirow[t]{2}{*}{ Ingredient } & \multirow{2}{*}{$\begin{array}{c}\text { Control } \\
\mathrm{T} 1\end{array}$} & \multicolumn{6}{|c|}{ Blends } \\
\hline & & T2 & T3 & T4 & T5 & T6 & T7 \\
\hline Corn Flour & 150 & 142.5 & 135 & 127.5 & 120 & 112.5 & 105 \\
\hline Rice Flour & 100 & 95 & 90 & 85 & 80 & 75 & 70 \\
\hline Chana Flour & - & 12.5 & 25 & 37.5 & 50 & 62.5 & 75 \\
\hline Salt & 4 & 4 & 4 & 4 & 4 & 4 & 4 \\
\hline Color & 1 & 1 & 1 & 1 & 1 & 1 & 1 \\
\hline Water & 15 & 15 & 15 & 15 & 15 & 15 & 15 \\
\hline
\end{tabular}

*Each sample prepared in 250gm 


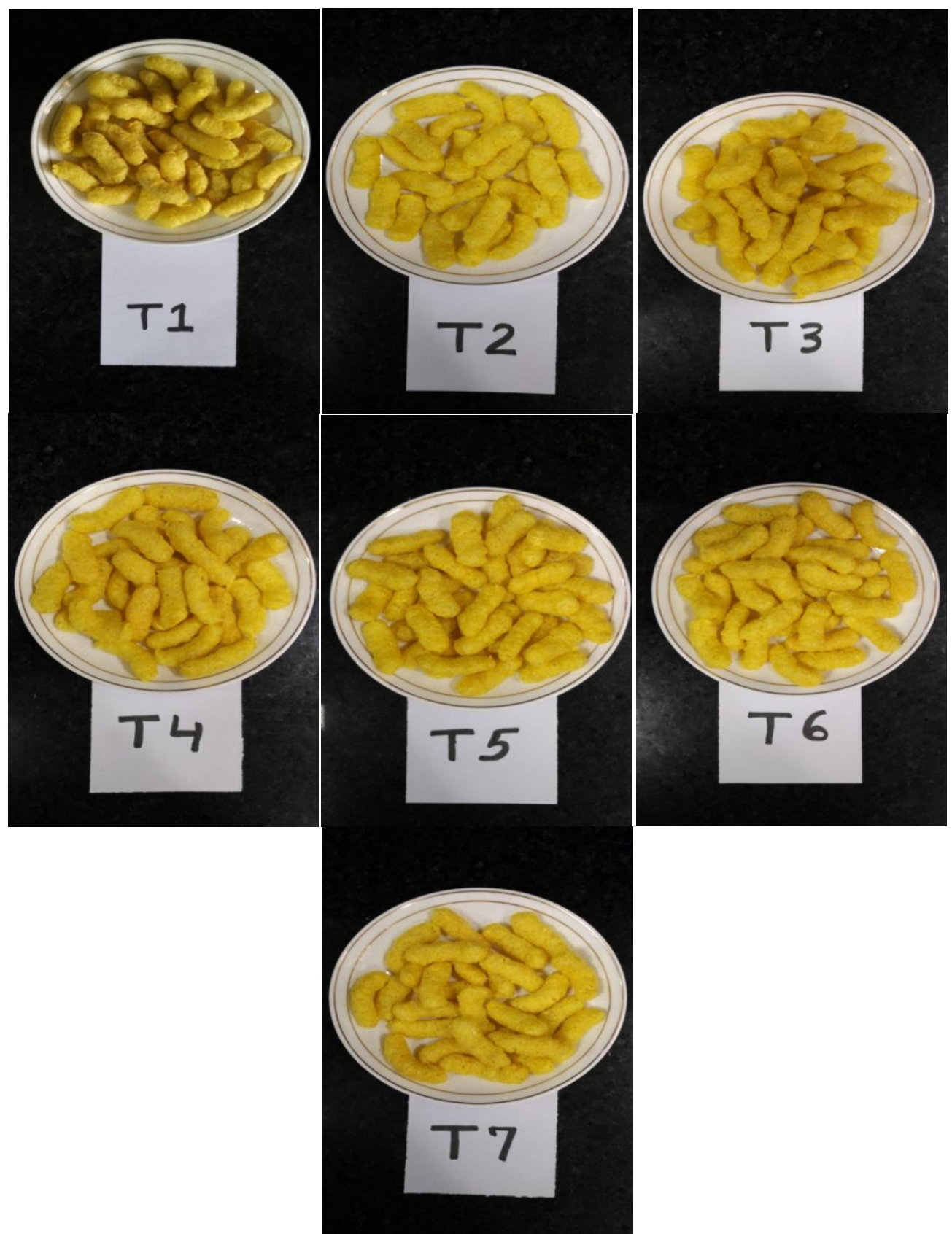

Figure 1. Extruded puff products

The RVA (Rapid Visco Analyzer of Perten, Sweden) was used to determine the pasting properties or different starch rheological properties (e.g. gelatinization) in cereals and starchy foods. The texture characteristics of exrudates were measured using a Stable Micro System, UK texture analyser (model TAXT2i). Each extrudate was placed on the heavy duty platform and the test speed was set to $2 \mathrm{~mm} / \mathrm{s}$ and the probe compressed $50 \%$ of the sample to measure the hardness.

\subsection{Characterization of the extruded samples}

The extruded samples were stored at room temperature in plastic ziplock bags. In all analytical determinations, the averages of three measurements were reported, except diameter, length, bulk density and expansion ratio. For these physical parameters ten samples each of the different products were taken for measurement and mean of the ten values were recorded. Length and diameter (in millimeter) of the selected extrudates was measured by using digital vernier calipers. The bulk density and expansion ratio were determined by using the equation-

$$
\text { Bulk density }=\frac{\text { weight } / \mathrm{gm}}{\text { volume } / \mathrm{ml}}
$$




$$
\text { Expansion ratio }=\frac{\text { diameter of extrudate } / \mathrm{mm}}{\text { diameter of the die } / \mathrm{mm}}
$$

\subsection{Chemical and Statistical analysis}

The samples were separately analyzed for proximate composition using the standard methods. Moisture content of flours and the extrudates was determined by I.S.I. 1984 [8]. Total ash was determined using procedure given by Association of Official Analytical Chemists method (AOAC, 1984) [9]. The extruded puffed products were freshly prepared and organoleptically evaluated by a panel of judges selected from Institute of Food Technology, Bundelkhand University, Jhansi. The products were judged for the quality such as colour, flavour, taste, texture and overall acceptability with the help of 9 point hedonic scale [10]. Statistical analyses were done in triplicate. Analysis of variance was performed to calculate significant difference in treatment means and LSD $(\mathrm{p}<0.05)$ was used separation means using SPSS version 16.0.

\section{Results And Discussions}

The diameter was observed to be in the range of $12.06 \pm 0.15$ to $14.13 \pm 0.73 \mathrm{~mm}$. The length of the extrudates ranged from $32.58 \pm 10.28$ to $38.52 \pm 1.40 \mathrm{~mm}$. The least diameter was observed for the control product made from corn and rice and in length product made from 5\% incorporation of chana flour. The bulk density of the product ranged from 0.0531 to $0.0610 \mathrm{gm} / \mathrm{cm} 3$. The highest value was observed for $30 \%$ chana flour and least for control sample. Higher the level of chana flour resulted in higher bulk density. Higher level of chickpea flour resulted in higher bulk density. Suksomboon et al. (2011) reported similar result while extruding purple rice flour blended with 5-15\% soybean [11]. Bulk density and expansion ratio of extrudates seek to describe the degree of puffing undergone by the dough as it exits the extruder. Minimum expansion ratio was seen for $30 \%$ chana flour sample after control sample and the maximum for the product made from 5\% chana incorporation. Increasing chana flour level resulted in reduction of expansion ratio. Nelson (2003) and Berrios (2010) reported that increasing the protein levels will lead to decrease in diameter and expansion ratio of the extrudates. Further, the increase in fat content of the blend or samples at higher chana flour level could also contribute to the reduction in expansion $[12 ; 13]$.

Table 2. Physical parameters of extruded products

\begin{tabular}{|c|c|c|c|c|}
\hline Samples & Diameter & Length & Bulk density & Expansion ratio \\
\hline T1 & $12.06 \pm 0.15$ & $35.09 \pm 2.39$ & $0.0531 \pm 0.0007$ & $4.01 \pm 0.51$ \\
\hline T2 & $14.13 \pm 0.73$ & $32.58 \pm 10.28$ & $0.0560 \pm 0.0000$ & $4.71 \pm 0.24$ \\
\hline T3 & $13.34 \pm 0.72$ & $38.41 \pm 2.64$ & $0.0563 \pm 0.0004$ & $4.45 \pm 0.24$ \\
\hline T4 & $13.30 \pm 0.80$ & $36.55 \pm 0.62$ & $0.0570 \pm 0.0000$ & $4.43 \pm 0.27$ \\
\hline T6 & $13.26 \pm 0.69$ & $38.52 \pm 1.40$ & $0.0576 \pm 0.0005$ & $4.42 \pm 0.23$ \\
\hline T7 & $13.10 \pm 0.70$ & $38.40 \pm 0.89$ & $0.0591 \pm 0.0007$ & $4.37 \pm 0.23$ \\
\hline SE \pm & $12.30 \pm 0.91$ & $34.03 \pm 0.84$ & $0.0610 \pm 0.0000$ & $4.10 \pm 0.30$ \\
\hline F Ratio & 0.1169 & 0.6235 & 0.0002 & 0.0389 \\
\hline T & $5.862^{*}$ & $3.377 *$ & $207.881^{*}$ & $5.863^{*}$ \\
\hline
\end{tabular}

Results are mean \pm SD of ten samples analysis. *The mean difference is significant at the $0.05(5 \%)$ level. ** Non-significant at $5 \%$.

The mean values of moisture, protein, fat, carbohydrates, fiber and ash content of samples were 8.098, $13.095,3.565,72.211,6.88$ and 2.982 respectively and all showing significant difference. These values are with in the range reported by other investigators [14], total lipid content is about $1.80-3.40 \%$. in our study the result are in conformity with those from literature, it is about $2.98 \%$. T7 sample is showing high protein content due to high level of chana flour incorporation. According to the scientific literature, the total protein content is about $17-22 \%$ [7] and the results (Table 3) indicate that the addition of chana flour increased protein content of samples from 6.42 to 19.81 . With the increased level of chana flour protein, ash, fat and dietary fiber is also increase except moisture and carbohydrates content.

Table 3. Proximate composition of extruded products

\begin{tabular}{|c|c|c|c|c|c|c|c|}
\hline Sample & Moisture & Ash & Protein & Fat & Carbohydrate & Dietary fiber & Hardness \\
\hline T1 & $10.92 \pm 0.02$ & $3.61 \pm 0.10$ & $6.42 \pm 0.07$ & $1.55 \pm 0.01$ & $77.50 \pm 0.18$ & $3.70 \pm 0.05$ & $1173.07 \pm 31.02$ \\
\hline T2 & $8.00 \pm 0.10$ & $2.30 \pm 0.26$ & $8.57 \pm 0.15$ & $2.15 \pm 0.10$ & $78.78 \pm 0.31$ & $4.60 \pm 0.20$ & $869.9 \pm 107.81$ \\
\hline T3 & $7.70 \pm 0.20$ & $2,57 \pm 0.06$ & $10.79 \pm 0.17$ & $2.75 \pm 0.20$ & $76.19 \pm 0.62$ & $5.78 \pm 0.08$ & $982.03 \pm 98.99$ \\
\hline T4 & $7.60 \pm 0.10$ & $2.73 \pm 0.15$ & $13.09 \pm 0.11$ & $3.49 \pm 0.16$ & $72.95 \pm 0.74$ & $6.77 \pm 0.15$ & $1067.8 \pm 61.61$ \\
\hline T5 & $7.57 \pm 0.06$ & $3.03 \pm 0.06$ & $15.36 \pm 0.11$ & $4.32 \pm 0.02$ & $69.72 \pm 0.23$ & $7.90 \pm 0.05$ & $1170.57 \pm 15.80$ \\
\hline T6 & $7.50 \pm 0.10$ & $3.27 \pm 0.12$ & $17.62 \pm 0.10$ & $5.03 \pm 0.02$ & $66.57 \pm 0.33$ & $8.97 \pm 0.04$ & $1207.07 \pm 8.48$ \\
\hline T7 & $7.40 \pm 0.10$ & $3.37 \pm 0.06$ & $19.81 \pm 0.15$ & $5.65 \pm 0.09$ & $63.77 \pm 0.39$ & $10.50 \pm 0.26$ & $1215.17 \pm 68.06$ \\
\hline Mean & 8.098 & 2.982 & 13.095 & 3.565 & 72.211 & 6.888 & 1097.9 \\
\hline SE \pm & 0.261 & 0.100 & 1.003 & 0.315 & 1.187 & 0.500 & 29.721 \\
\hline F Ratio & $397.379^{*}$ & $36.965^{*}$ & $4.429^{*}$ & $569.791^{*}$ & $502.572^{*}$ & $835.104^{*}$ & $11.569^{*}$ \\
\hline
\end{tabular}


Hardness is the peak force required for a probe to penetrate the extrudate. The range of hardness found to be $869.9 \mathrm{~g}$ to $1215.17 \mathrm{~g}$ (Table 3 ) by which we can say that the more force required to breakdown the sample with increasing amount of chana flour. Higher density product naturally offers more hardness evident by higher correlation between product density and hardness.

Table 4. Means score for different sensory attributes of developed products

\begin{tabular}{|c|c|c|c|c|c|}
\hline Samples & Colour & Flavour & Texture & Taste & $\begin{array}{c}\text { Overall } \\
\text { Acceptability }\end{array}$ \\
\hline T1 & $6.75 \pm 0.72$ & $7.05 \pm 0.80$ & $6.95 \pm 0.93$ & $7.15 \pm 0.75$ & $6.98 \pm 0.51$ \\
\hline T2 & $7.65 \pm 0.58$ & $7.30 \pm 0.92$ & $7.30 \pm 0.95$ & $7.75 \pm 0.79$ & $7.50 \pm 0.48$ \\
\hline T3 & $7.75 \pm 1.18$ & $7.30 \pm 0.89$ & $7.75 \pm 0.79$ & $7.60 \pm 0.99$ & $7.60 \pm 0.64$ \\
\hline T4 & $8.05 \pm 0.93$ & $7.45 \pm 0.76$ & $7.90 \pm 0.94$ & $7.45 \pm 0.83$ & $7.70 \pm 0.62$ \\
\hline T5 & $7.90 \pm 0.77$ & $7.80 \pm 0.63$ & $8.05 \pm 0.83$ & $7.80 \pm 0.48$ & $7.89 \pm 0.48$ \\
\hline T6 & $7.85 \pm 0.71$ & $7.10 \pm 0.84$ & $7.90 \pm 0.97$ & $7.90 \pm 0.61$ & $7.69 \pm 0.52$ \\
\hline T7 & $7.50 \pm 0.82$ & $7.35 \pm 1.00$ & $8.25 \pm 0.79$ & $8.15 \pm 0.75$ & $7.72 \pm 0.64$ \\
\hline SE \pm & 0.11 & 0.10 & 0.11 & 0.09 & 0.07 \\
\hline F Ratio & $2.638^{*}$ & $0.866^{* *}$ & $2.592^{*}$ & $1.818^{* *}$ & $2.713^{*}$ \\
\hline
\end{tabular}

Results are mean \pm SD of ten samples analysis. *The mean difference is significant at the $0.05(5 \%)$ level. ** Non-significant at $5 \%$.

The sensory attributes of all the samples were judged with maximum and minimum scores of samples when compared to other samples. Sensory evaluation revealed that T5 had the highest ranking scores in all the 5 -attributes. Overall the most accepted sample had a mean flavour score of 7.80 and was produced with $20 \%$ chana flour level. This product had a mean value of 0.0576 and 4.42 for bulk density and expansion ratio. On the other hand in the case of texture or crispness $30 \%$ incorporation was considered as best among the six incorporations.

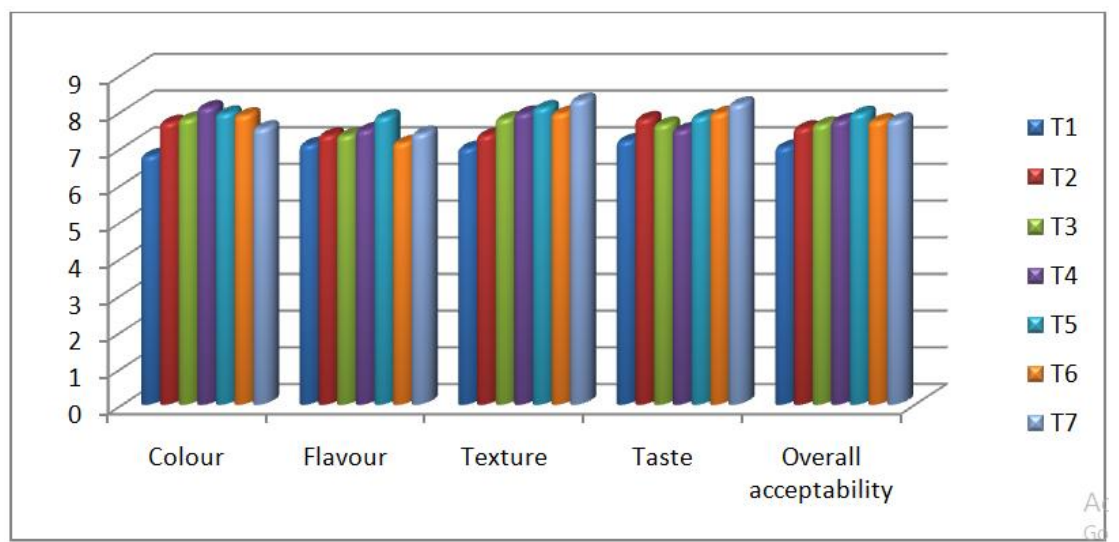

Figure 2. Response of the treatments on physiological characters of extruded puff products

\subsection{Visco-elastic properties}

The objective of this study was to compare the pasting properties of corn flour, rice flour and chana flour using the Rapid Visco Analyse (RVA). The RVA provides an index of rheological properties of sample is by re-cooking under relatively low shear in excess water and measuring the pasting viscosity throughout the test. The pasting properties determine the functional properties of the starch in the raw material and in the different industrial application. The RVA study of the raw samples showing their peak, hold and final viscosity along peak time are given in Table No.5. A high peak viscosity of $2977 \mathrm{cP}$ was observed in rice flour, while the least peak viscosity of $675 \mathrm{cP}$ was recorded in chana flour. A high peak viscosity is typical of gelatinized starch products and low moisture content processing, which indicates a high level of polymer breakage. The very low peak viscosity of the material can be explained by the protein content. However, peak and final viscosity of the flours decreased with increase in protein content. The hold period sometimes referred to as shear thinning, holding strength or hot paste viscosity is a period when the samples were subjected to a period of constant temperature and mechanical shear stress. It ranged from $642.67 \mathrm{cP}$ in chana flour sample to $2078.67 \mathrm{cP}$ (rice flour sample). A final viscosity range from $751.33 \mathrm{cP}$ to $4713.67 \mathrm{cP}$ observed in this study. Viscosity values of $3262.67 \mathrm{cP}$ for corn flour, $4713.67 \mathrm{cP}$ for rice flour and $751.33 \mathrm{cP}$ for chana flour. Peak time increased with protein content and it is measure of the cooking time. Peak time increased from 5.24 (rice flour) to 6.63 (chana flour). Peak time increased with increased in the level of protein content in the flour. 
Table 5. Pasting viscosity of raw materials

\begin{tabular}{|c|c|c|c|c|}
\hline Flour Samples & Peak Viscosity $(\mathbf{c P})$ & Hold Viscosity $(\mathbf{c P})$ & Final Viscosity $(\mathbf{c P})$ & Peak Time (min) \\
\hline Rice Flour & 2977.00 & 2078.67 & 4713.67 & 5.24 \\
\hline Corn Flour & 1224.67 & 1020.33 & 3262.67 & 5.38 \\
\hline Chana Flour & 675.00 & 642.67 & 751.33 & 6.63 \\
\hline Mean & 1625.56 & 1247.22 & 2909.22 & 5.75 \\
\hline SE \pm & 349.51 & 215.70 & 579.78 & 0.23 \\
\hline F Ratio & $210.72 *$ & $397.51 *$ & $810.35^{*}$ & $32.52^{*}$ \\
\hline
\end{tabular}

(a)Rice Flour

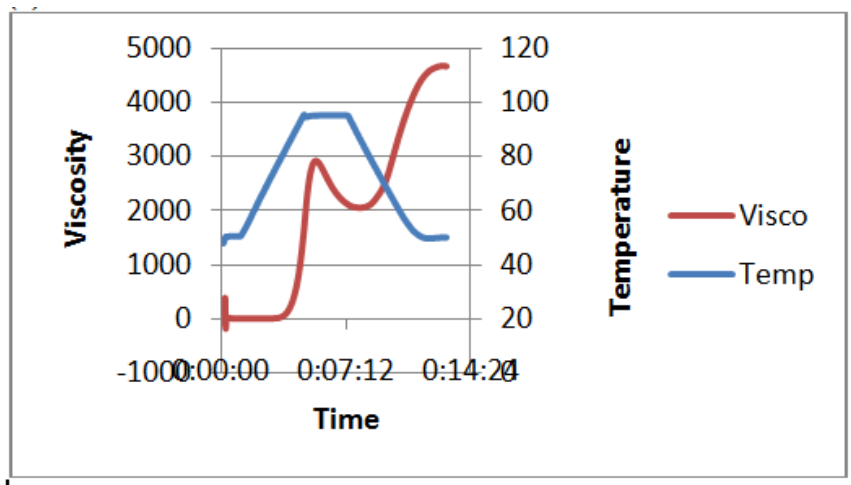

(b) Corn Flour

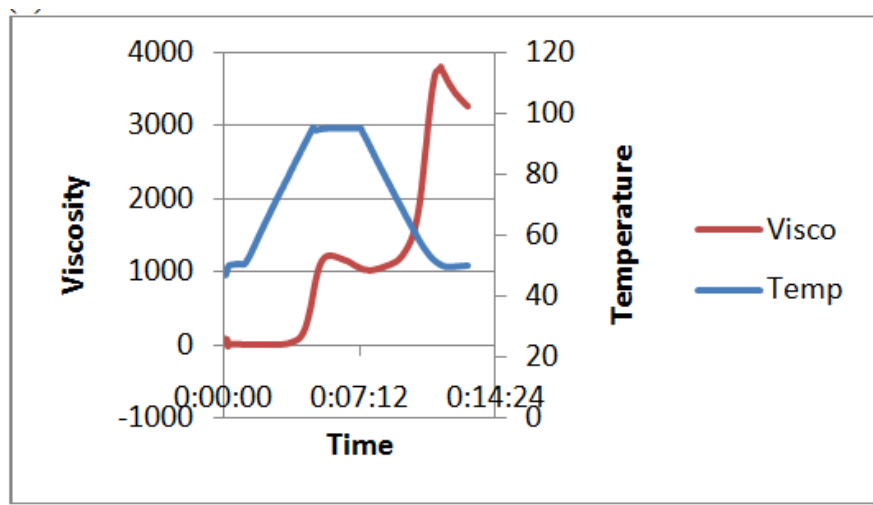

(c)Chana Flour

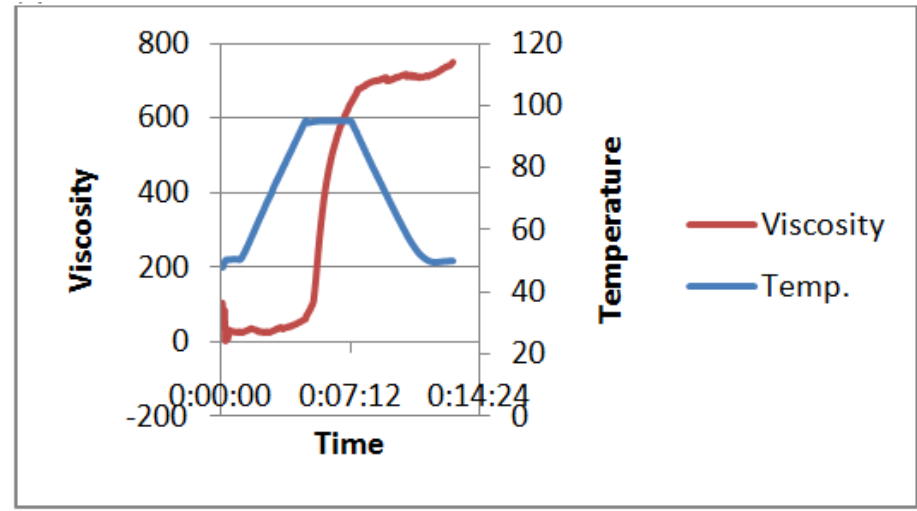

Figure 3. viscosity profiles: (a)Rice flour, (b) Corn flour, (c) Channa flour

\section{Conclusion}

The incorporation of chana flour at different levels in the pre standardized flour of rice and corn produces acceptable extrudates or puff snacks. The extrudates made from $20 \%$ incorporation of chana flour showed better functional properties as compared to all other treatments. The present study showed that the puff products made by incorporation of chana flour are suitable for childrens too since they are nutritious with regard to quantity and quality of the protein and energy content. There is no or minimum amount of added fat and due to non fried nature of the products they are more acceptable in our health conscious society. It was found that 
the extrudates of 20 percent chana flour were good in taste and healthy. Based on the results found in RVA analysis, it was also concluded that the chana flour had low peak viscosity due to high protein content.

\section{References}

[1] Havck, B.W. \& Huber, G.R. (1989). Single screw vs twin screw extrusion. The American Association of Cereal Chemists, 34, 930939.

[2] Castells, M., Marin, S., Sanchis, V. and Ramos, A.J. (2005). Fate of mycotoxins in cereals during extrusion cooking: a review. Food Additives and Contamination, 22, 150-157.

[3] Ali, Y., Hanna, M. A. and Chinnaswamy, R. (1996). Expansion characteristics of extruded corn grits. Lebensmittel-Wissenschaft und- Technologie 29,702-707.

[4] Hern'andez-D'iaz, J.R., Quintero-Ramos, A., Barnard, J. and Balandran-Quintana, R.R. (2007). Functional properties of extrudates prepared with blends of wheat flour/pinto bean meal with added wheat bran. Food Science and Technology International 13, 301308

[5] Brncic, M., B. Tripalo, S. Rimac Brncic, S. Karlovic, A. Zupan and Z. Herceg, (2009). Evaluation of textural properties for whey enriched direct extruded and puffed corn based products. Bulg. J. Agric. Sci., 15: 204-214

[6] Hulse JH (1991). Nature, composition and utilization of pulses. In Uses of Tropical Grain Legumes, Proceedings of a Consultants Meeting. AP. India: ICRISAT:11-27.

[7] Jukanti AK, PM Gaur, CLL Gowda, RN Chibbar (2012). Nutritional quality and health benefits of chickpea (Cicer arietinum L.): a review. British Journal of Nutrition Vol. 108. S1:S11-S26.

[8] I.S.I Handbook of Food Analysis (Part VIII), (1984). Determination of Moisture in Dehydrated Vegetables. page 12

[9] [AOAC] Official methods of analysis of the Association of Official Analytical Chemists. (1984). 14th edition. Washington, DC: Association of Official Analytical Chemists.

[10] Srilakshami, B., Sensory Evaluation” Food Science 4th Ed., (2007), Pp 286-297, 246-256.

[11] Suksomboon, A., Limroongreungrat, K. Sangnark, A. Thititumjariya, K. and Noomhorm, A. 2011. Effect of extrusion conditions on the physicochemical properties of a snack made from purple rice (Hom Nil) and soybean flour blend. International Journal of Food Science and Technology 46: 201-208.

[12] Nelson, M. (2003). Protein rich extruded snack foods using hydrolyzed proteins. American Psychological Association. 1-55.

[13] Berrios, J. J., Morales, P., Cámara, M., and Sánchez-Mata, M.C. (2010). Carbohydrate Composition of Raw and Extruded Pulse Flours. Food Res. Int. 43 (2): 531-536.

[14] Hefnawy TMH, El-Shourbagy GA, Ramadan MF (2012). Impact of adding chickpea (Cicer arietinum L.) flour to wheat flour on the rheological properties of toast bread. International Food Research Journal 19(2): 521-525. 